\title{
Patient Empanelment: The Importance of Understanding Who Is at Home in the Medical Home
}

Kevin Grumbach, MD, and J. Nwando Olayiwola, MD, MPH

The policy brief by Peterson et $\mathrm{al}^{1}$ in this issue of the Fournal of the American Board of Family Medicine presents a concise and provocative analysis of panel size estimation by family physicians. Empanelment is a foundational building block of high-performing primary care. ${ }^{2}$ Family physicians need to know the patients they are serving. One essential piece of information is the number of patients in their primary care practice-commonly referred to as "panel size". ${ }^{3}$ By asking 1 simple question of family physicians, "Approximately what is the size of your patient panel?" the authors found that only about one-third of respondents who provide direct patient care could estimate their panel size. It is startling that so few of these family physicians could give even a rough estimate of the number of patients active in their practice.

Among the minority who provided panel size estimates, larger panel sizes were associated with spending more time in direct patient care. However, there was wide variation in panel sizes estimated by family physicians reporting a similar amount of time spent in patient care. For example, of the family physicians reporting $61 \%$ to $80 \%$ of their time spent in direct patient care, about as many estimated panel sizes of $0-1000$ patients as

From the Center for Excellence in Primary Care, Department of Family and Community Medicine, University of California, San Francisco.

Funding: none.

Conflict of interest: none declared.

Corresponding author: Kevin Grumbach, MD, Department of Family and Community Medicine, University of California, San Francisco, San Francisco General Hospital, Ward 83, 1001 Potrero Ave, San Francisco, CA 94110 (E-mail: kgrumbach@fcm.ucsf.edu).

\section{See Related Article on Page 173.}

estimated panel sizes of 2501 to 4500 . This variation is not readily explained by part-time versus full-time activity and may be influenced by differences across physicians in the patient case mix; the extent of involvement of nurse practitioners, physician assistants, and other team members sharing the work of managing the patient panel; and other factors. However, given the difficulty so many of the respondents had in estimating panel size, we suspect that much of the variation reflects inattention to systematically measuring, standardizing, and addressing panel size as a core element of practice management. As Peterson et al pointed out, nearly $70 \%$ of these family physicians have an electronic health record, so the technology for panel size estimation is certainly present. Availability of technology does not guarantee that it is optimized.

\section{The Importance of Empanelment}

The findings of this research brief provide a timely wakeup call to family physicians and other primary care physicians (PCPs) to pay more attention to empanelment in their practice transformation efforts. Because PCPs are being held increasingly responsible for population management, prompt access, care coordination, and other advanced primary care or Patient-Centered Medical Home functions, it is essential that they identify who is at home in the medical home to help determine what to do for these empanelled patients-that is, PCPs must have full awareness of the population of patients for whom they are accountable to achieve many higher level advanced primary care functions.

Empanelment is a vital enabler of many elements of high-performing primary care. ${ }^{2}$ Empanelment formalizes a continuity relationship between patients and their PCP-led team and medical home. It provides a population denominator for measuring and holding PCPs accountable for qual- 
ity of care, such as the percentage of patients upto-date on breast cancer screening, and for guiding population health management, such as by identifying patients with diabetes with poor glycemic control who might benefit from targeted outreach by health coaches. Empanelment helps practices address access issues by balancing supply with demand for services, including by prioritizing appropriate task delegation among practice staff in teambased care models tailored to the needs of the patient panel. ${ }^{3-5}$ These enhanced functionalities may, in turn, lead to improved clinical outcomes, reduced costs, and, potentially, enhanced revenue per visit. ${ }^{3,4}$ Knowing "who is at home in the medical home" facilitates a more robust framework for delivering timely, coordinated, and high-quality primary care and determining the appropriate capacity of the medical home for the size and characteristics of the panel of patients it serves.

\section{Policies to Promote Formal Registration and Empanelment}

Empanelment is most readily achieved when there is a formal process for registering patients with a PCP. Registration is required when PCPs are paid by capitation: A patient must designate a PCP, and this designation triggers monthly capitation payments from the payer to the practice. Many national health systems, such as those in the United Kingdom, Denmark, and the Netherlands, have institutionalized capitation payment with universal, compulsory patient registration with PCPs. This approach has the advantage of allowing PCPs to use these registration rosters to precisely identify all their empanelled patients and measure panel sizes.

Identifying empanelled patients is more challenging in fee-for-service environments. Part of the political culture of fee-for-service payment is free choice of a provider by patients at the point of service. PCPs in fee-for-service environments tend to estimate panel sizes on the basis of tallies of patients with visits to the practice within a certain time frame- often using 1 or more visits within the prior 2 years to indicate an "active" patient in the practice. This method has the imprecision of not counting patients who are infrequent users of services but may still consider themselves empanelled to a PCP and including patients who may have transferred to another medical home since their last visit to the PCP within the previous 2 years.
Some nations that have traditionally paid feefor-service have moved in recent years toward universal PCP empanelment. In Canada, for example, the Ontario Provincial Health Plan has sought to promote primary care group practices and to shift payment to PCPs from fee-for-service to capitation. Because of political resistance to compulsory registration with a medical home, Ontario has encouraged voluntary registration with family medicine groups under blended payment models that include a component of capitation. More than $75 \%$ of Ontario residents are now formally empanelled to PCPs on a voluntary basis. ${ }^{6}$

The pluralistic approach to health insurance and physician payment in the United States complicates efforts to achieve universal empanelment of patients with a medical home. Capitation payment has long been a feature of many health maintenance organization (HMO) plans in the United States. However, the US approach to capitation has not been entirely successful in promoting universal empanelment. Patients in HMOs are typically a minority of the patients cared for by a PCP; roster data from HMO plans or intermediary medical groups provide a very incomplete picture of the entire panel of patients cared for by the PCP. Moreover, capitation payments often flow from the $\mathrm{HMO}$ to a medical group or independent practice association, which may in turn pay the PCP on a fee-for-service basis. This dilutes the power of capitation payment for tightly empanelling patients with PCPs, and PCPs often find their lists of empanelled patients provided by the HMO or medical group notoriously inaccurate. "Direct payment" is a newer form of capitation, in which individual patients or an employer on behalf of employees directly pays a capitation fee to a PCP, creating a tighter link between the capitation payment and empanelment. PCPs who exclusively practice under a direct payment model can reasonably accurately measure panel sizes on the basis of registration data.

Although the United States has not yet demonstrated the resolve of some other nations in promoting universal, or near-universal, formal registration of patients with PCPs, payers in the United States are gradually implementing reforms that are moving in this direction. Health plans involved in Patient-Centered Medical Home initiatives have fostered voluntary patient registration with PCPs under blended payment models that include a 
capitated care-coordination payment. Accountable Care Organization shared-risk payment models often continue to rely on fee-for-service as the base payment but retrospectively attribute patients to delivery organizations and their PCPs on the basis of where patients predominantly receive their care-a crude form of empanelment.

\section{Conclusions}

Knowing "who is at home in the medical home" is critical to achieving high-performing primary care. Family physicians and other PCPs need to identify their active patients and measure panel sizes, even in the face of imperfect data. Payers and policy makers, for their part, must take bolder actions to move the nation toward universal registration of patients with a PCP and medical home. These actions may consist of both carrots, such as offering patients in fee-for-service plans a small rebate on their insurance premium or similar incentive to formally register with a PCP, and sticks, such as mandatory registration with a PCP reinforced by capitation or similar physician-payment policies that encourage patient fidelity to a selected medical home. The Family Medicine for America's Health initiative recently launched by the major US family medicine organizations calls for linking every patient with a "personal" PCP and medical home and broad adoption of "comprehensive" payment mod- els for primary care that move away from pure fee-for-service and include a component of capitation. ${ }^{7}$ Among the benefits of such payment reform would be strengthening processes for formal empanelment of patients to medical homes.

\section{References}

1. Peterson L, Cochrane A, Bazemore A, Baxley E, Phillips RL Jr. Only one-third of family physicians can estimate their patient panel size. J Am Board Fam Med 2015;28;173-4.

2. Bodenheimer T, Ghorob A, Willard-Grace R, Grumbach K. The 10 building blocks of high-performing primary care. Ann Fam Med 2014;12: 166-71.

3. Muldoon L, Dahrouge S, Russell G, Hogg W, Ward N. How many patients should a family physician have? Factors to consider in answering a deceptively simple question. Healthc Policy 2012;7:26-34.

4. Murray M, Davies M, Boushon B. Panel size: how many patients can one doctor manage. Fam Pract Manag 2007;14:44-51.

5. Altschuler J, Margolius D, Bodenheimer T, Grumbach K. Estimating a reasonable patient panel size for primary care physicians with team-based task delegation. Ann Fam Med 2012;10:396-400.

6. Hutchison B, Glazier R. Ontario's primary care reforms have transformed the local care landscape, but a plan is needed for ongoing improvement. Health Aff (Millwood) 2013;32:695-703.

7. Phillips RL Jr, Pugno PA, Saultz JW, et al. Health is primary: family medicine for America's health. Ann Fam Med 2014;12(suppl 1):S1-S12. 